\begin{tabular}{|c|c|}
\hline \multicolumn{2}{|c|}{ 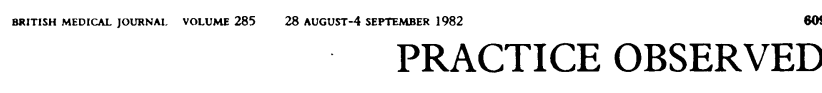 } \\
\hline \multicolumn{2}{|c|}{ Research in General Practice } \\
\hline \multicolumn{2}{|c|}{$\begin{array}{l}\text { Sterilisation of women: prevalence and outcome } \\
\text { ALASTAIR F WRIGHT }\end{array}$} \\
\hline Why I stared & 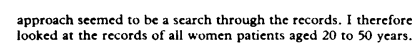 \\
\hline 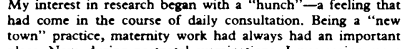 & 为 \\
\hline 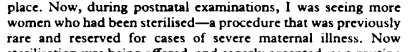 & 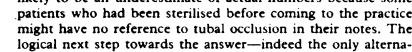 \\
\hline 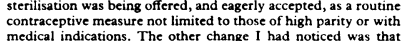 & 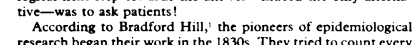 \\
\hline 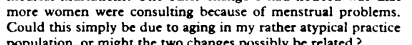 & 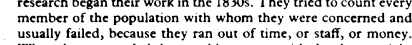 \\
\hline 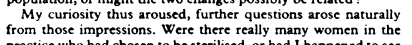 & 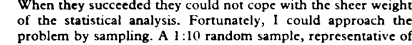 \\
\hline 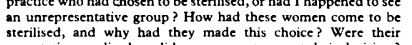 & 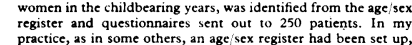 \\
\hline 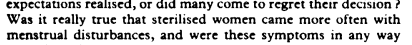 & 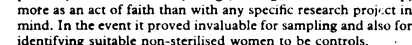 \\
\hline 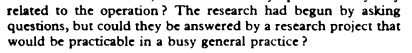 & 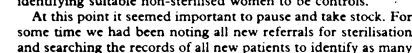 \\
\hline & 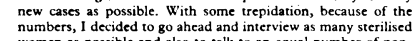 \\
\hline 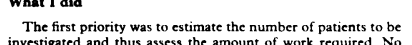 & 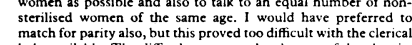 \\
\hline 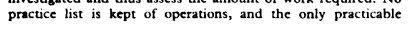 & 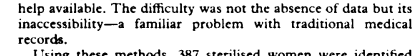 \\
\hline 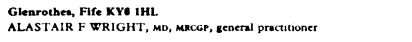 & 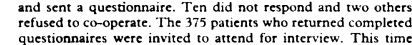 \\
\hline
\end{tabular}
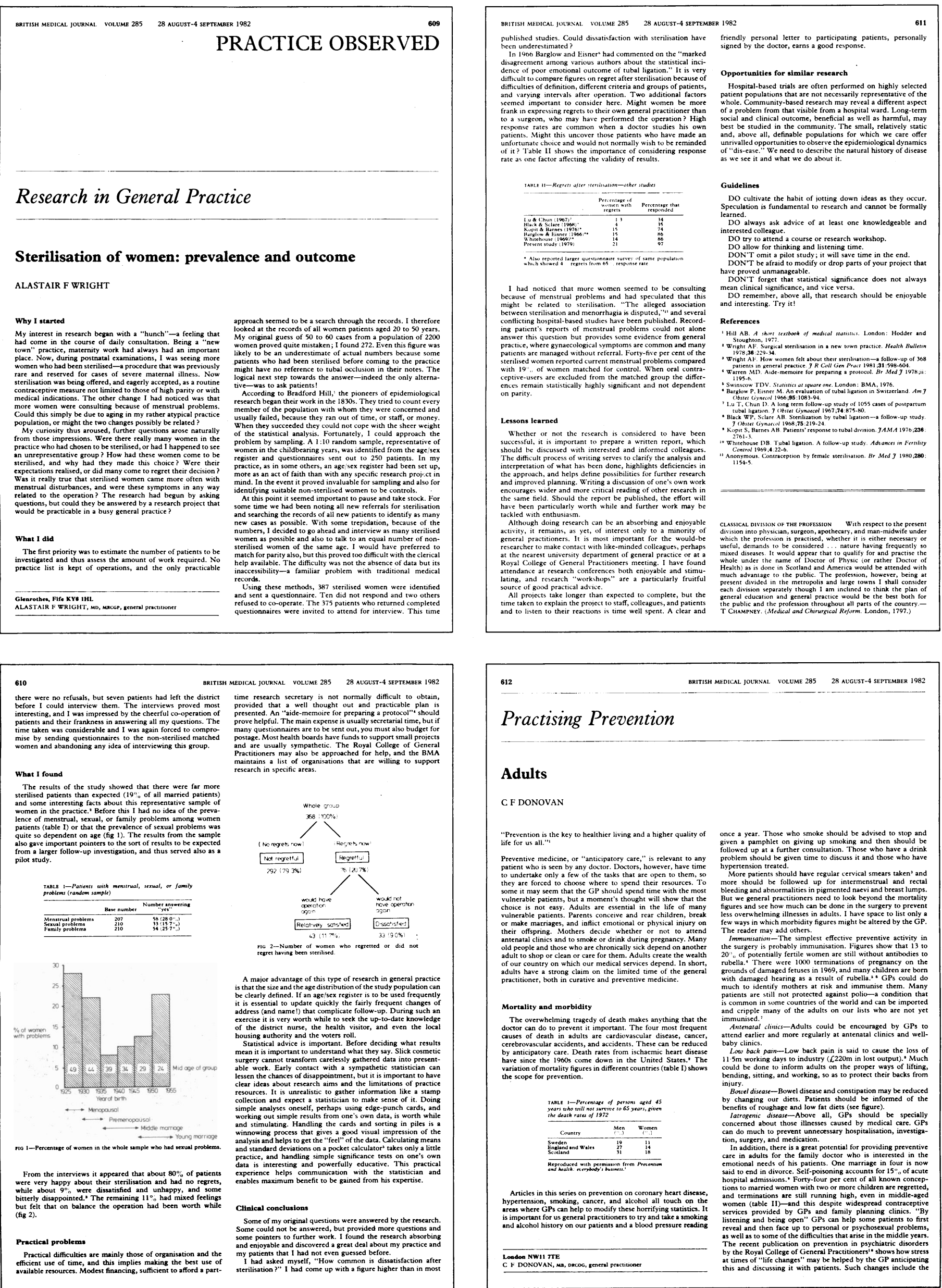

612

\section{Practising Prevention}

\section{Adults}

CF DONOVAN

"Prevention is the key to healthicr living and a higher quality of
life for us all."

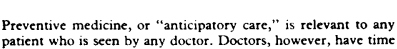

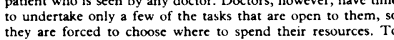

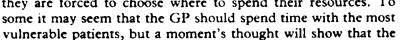

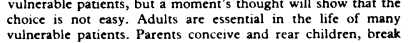

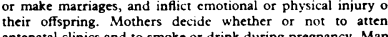

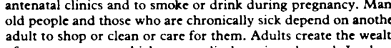

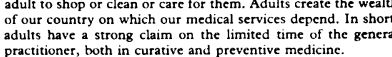

The overwhelming tragedy of death makes anything that the
docotor can do o p prevern tit imporant. The four most frequent

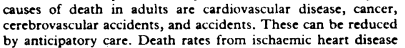

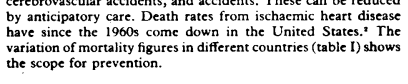

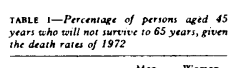

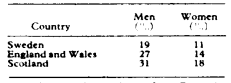

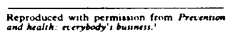

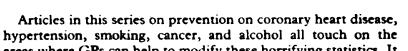

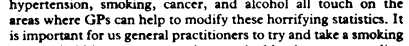

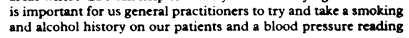

Loodon NW11 TRE
C F DONOVAN, MA, DicoG, general practitioner

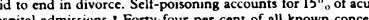

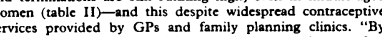

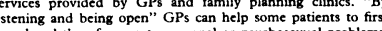

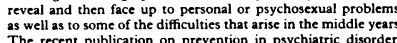

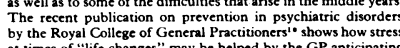

BRITISH MEDICAL JOURNAL VOLUME $285 \quad 28$ AUGUST-4 SEPTEMBER 1982

practitioner, both in curatice lons to married women with two or morc childeren are regreteted,
and terminations

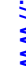

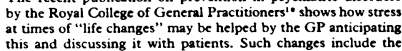

